\title{
$\checkmark$ Research Square \\ Concept of a Fast Breeder Reactor To Transmute MA and LLFP
}

Toshio Wakabayashi ( $\nabla$ toshio.wakabayashi.c1@tohoku.ac.jp )

Tohoku University

\section{Research Article}

Keywords: fast breeder reactor, nuclear power systems, uranium, radioactive waste, fuel

Posted Date: May 18th, 2021

DOl: https://doi.org/10.21203/rs.3.rs-523677/v1

License: (c) (i) This work is licensed under a Creative Commons Attribution 4.0 International License. Read Full License 


\title{
Concept of a fast breeder reactor to transmute MA and LLFP
}

\author{
Toshio Wakabayashi ${ }^{1}$
}

${ }^{1}$ Tohoku University, Graduate School of Engineering, 6-6-11 Aoba, Aramaki, Aoba-ku, Sendai, Miyagi, 980-8579, Japan.

Correspondence and requests for materials should be addressed to T.W. (email: toshio.wakabayashi.c1@,tohoku.ac.jp)

\begin{abstract}
The long-term issues of nuclear power systems are the effective use of uranium resources and the reduction of radioactive waste. Important radioactive wastes are minor actinides (MA: ${ }^{237} \mathrm{~Np},{ }^{241} \mathrm{Am}$, ${ }^{243} \mathrm{Am}$, etc.) and long-lived fission products (LLFP: ${ }^{129} \mathrm{I},{ }^{99} \mathrm{Tc},{ }^{79} \mathrm{Se}$, etc.). The purpose of this study was to show a system that can simultaneously achieve the breeding of fissile materials and the transmutation of MA and LLFP in one fast reactor. Transmutation was carried out by loading innovative Duplex type MA fuel in the core region and LLFP containing moderator in the first layer of the radial blanket. Breeding was achieved in the core and axial blanket. As a result, it was clarified that in this fast breeder reactor, a breeding ratio of about 1.1 was obtained, and MA and LLFP achieved a support ratio of 1 or more. The transmutation rate was $10.3 \% / \mathrm{y}$ for ${ }^{237} \mathrm{~Np}, 14.1 \% / \mathrm{y}$ for ${ }^{241} \mathrm{Am}, 9.9 \% / \mathrm{y}$ for ${ }^{243} \mathrm{Am}, 1.6 \% / \mathrm{y}$ for ${ }^{129} \mathrm{I}, 0.75 \% / \mathrm{y}$ for ${ }^{99} \mathrm{Tc}$, and $4 \% / \mathrm{y}$ for ${ }^{79} \mathrm{Se}$. By simultaneously breeding fissile materials and transmuting MA and LLFP in one fast reactor, it will be possible to solve the long-term issues of the nuclear power reactor system, such as securing nuclear fuel resources and reducing radioactive waste.
\end{abstract}

\section{Introduction}

Important issues for nuclear power generation are the effective use of uranium resources and the reduction of radioactive waste while ensuring safety. For the effective use of uranium resources, the fast breeder reactor (FBR) can convert ${ }^{238} \mathrm{U}$ to fissile material, such as ${ }^{239} \mathrm{Pu}$, with a breeding ratio of 1 or more.

In order to reduce radioactive waste, it is important to reduce the amounts of minor actinides (MA: ${ }^{237} \mathrm{~Np},{ }^{241} \mathrm{Am},{ }^{243} \mathrm{Am}$, etc.) and long half-lived fission products (LLFP: ${ }^{99} \mathrm{Tc},{ }^{129} \mathrm{I},{ }^{79} \mathrm{Se}$, etc.). In backend research, MA is the major element of the potential toxicity of the radioactive waste. By recovering and transmuting minor actinide nuclides, it is thought that the potential toxicity after 1000 years can be reduced to $1 / 100$. In addition, the removal of MA is said to be effective in reducing the area of the 
disposal site. On the other hand, LLFP is regarded as important from the viewpoint of the radiation safety performance (future exposure dose to the public) of the disposal site.

Many studies have been conducted on the transmutations of MA and LLFP in fast reactors ${ }^{1-31}$. Regarding MA, it is known that if an average of about $5 \%$ of MA was added to the fuel region, a transmutation rate of $10 \% / y$ or more was achieved without significantly affecting the core characteristics $^{7,13}$.

Regarding LLFP, a transmutation study has recently been conducted on 6 important nuclides $\left({ }^{79} \mathrm{Se}\right.$, ${ }^{93} \mathrm{Zr},{ }^{99} \mathrm{Tc},{ }^{107} \mathrm{Pd},{ }^{129} \mathrm{I}$, and ${ }^{135} \mathrm{Cs}$ ) from the viewpoint of reducing environmental influence. As a result, it was shown that the fast reactor can be used to transmute each of these 6 nuclides with a support ratio exceeding 1 using the $\mathrm{YD}_{2}$ moderator ${ }^{28}$. The significant reduction in the effective half-life was obtained by analysis. In this case, the six nuclides were used as elements without isotope separation. In addition, a method that can transmute six nuclides at the same time with a support ratio of 1 or more in one fast reactor was clarified ${ }^{29}$. In this case, ${ }^{135} \mathrm{Cs}$ and ${ }^{93} \mathrm{Zr}$, both with small neutron absorption cross sections were placed in the radial blanket region, and ${ }^{129} \mathrm{I}$ and ${ }^{99} \mathrm{Tc}$, both with large neutron absorption cross sections were placed in the shield region and axial blanket away from the fuel region Therefore, the transmutation rate of all nuclides was less than $0.5 \% / y$. On the other hand, a study on a method designed to achieve a high transmutation rate (about $8 \% / \mathrm{y}$ ) for four nuclides $\left({ }^{79} \mathrm{Se},{ }^{99} \mathrm{Tc},{ }^{107} \mathrm{Pd},{ }^{129} \mathrm{I}\right)$ was conducted ${ }^{30}$. Based on these studies, a system that further improves the transmutation efficiency of the six nuclides was explored. A fast reactor LLFP transmutation system that achieves a support ratio of 1 or more for the entire system was constructed by combining three fast reactors, in addition to using one reactor ${ }^{31}$. From these studies, a significant amount of information about the LLFP transmutation system was obtained.

Among these LLFP nuclides, ${ }^{129}$ I presents a long-term radioactivity problem in geological disposal as a long-lived nuclide that is soluble and less absorbed by underground materials ${ }^{32} .{ }^{99} \mathrm{Tc}$ is the main radioisotope of vitrified radioactive waste, and its potential toxicity is a problem. ${ }^{79} \mathrm{Se}$ has been a determinant of radiation exposure over the period of $10^{4}-10^{5}$ years. Reducing these three nuclides could reduce the uncertainty of geological disposal. Therefore, these three nuclides were selected as LLFP for transmutation in this study.

If breeding of fissile materials and transmutation of MA $\left({ }^{237} \mathrm{~Np},{ }^{241} \mathrm{Am},{ }^{243} \mathrm{Am}\right)$ and LLFP $\left({ }^{129} \mathrm{I},{ }^{99} \mathrm{Tc}\right.$, ${ }^{79} \mathrm{Se}$ ) can be performed simultaneously in one fast reactor, the long-term issues of securing nuclear fuel resources for nuclear power systems and reducing radioactive waste would be solved. In addition, solution of these issues would lead to a better understanding of nuclear power generation among the general public. The purpose of this study was to show a system that simultaneously achieves the breeding of fissile materials and the transmutation of MA and LLFP in one fast breeder reactor.

Here, the support ratio (SR) was defined as the ratio of the amount of each nuclide transmuted by the fast breeder reactor to the amount of each nuclide (MA and LLFP) produced by the fast breeder 
reactor $^{28,30,31}$.

\section{Results and discussions}

Studies on MA transmutation in fast reactors have investigated homogeneous loading, in which MA is homogeneously added to the core fuels, and heterogenous loading, in which assemblies of only MA are loaded in the core in a dispersed manner. In the case of homogeneous loading, the effect on the power distribution in the core is small, but due to the strong radiation of MA, large-scale shielded cells were required to prevent exposure during manufacturing. In the case of heterogenous loading, the MA assemblies with large neutron absorption cross sections and the normal MOX fuel assemblies were mixed, so the difference in power among these was large and it was difficult to control the power distribution in the core.

Therefore, Duplex type MA fuel was proposed as an innovative alternative. The concept of the MA fuel is to insert the MA pellet into the center of the hollow MOX pellet, as shown in Fig.1 (a). This is called a Duplex pellet. Normal hollow MOX pellets can be manufactured in glove boxes that do not require significant shielding to prevent high radiation exposure. The central MA pellets are manufactured and inserted into the Duplex pellets in small shielding cells. Since hollow MOX pellets can be manufactured in glove boxes, it is expected that the manufacturing equipment will be simplified compared to MA homogeneous fuels, leading to a reduction in manufacturing costs. Figure. 1 (a) shows the structure of the MA-containing MOX fuel assembly. The number of MA fuel pins in the MA fuel assembly was 271 . The MA content of the central MA pellet was set to $20 \mathrm{wt} \%$ so that the average of MOX and MA pellets was $5 \mathrm{wt} \%$. The MA containing MOX fuel assemblies were loaded in the inner and outer cores. Figure 2 shows the arrangement of MA-containing fuel assemblies in the fast breeder reactor core. Regarding the fabrication of Duplex pellets, studies were conducted on the effects of $\mathrm{Gd}_{2} \mathrm{O}_{3}$ placed in the center of oxide fuel pins in $\mathrm{LWR}^{33,34}$. In addition, by using Duplex pellets containing neutron absorbers in fast reactors, a new core concept has been proposed that did not achieve re-criticality in case of fuel melting in an accident ${ }^{35}$. From these studies, it is considered that the innovative Duplex type MA fuel used in MA transmutation is sufficiently feasible.

Regarding the transmutation of LLFP, LLFP assemblies in which moderators ${ }^{36-40}\left(\mathrm{YH}_{2}, \mathrm{YD}_{2}\right.$, etc.) were combined with LLFP nuclides have been studied in order to improve the transmutation performance of LLFP. When an LLFP assembly that combines LLFP and $\mathrm{YH}_{2}$ moderator is loaded in the blanket region, $\mathrm{YH}_{2}$ has a high moderating ability, so the transmutation rate increases. However, an increase in the amount of thermal neutrons would create a thermal spike by causing the power of the adjacent fuel assembly to increase. In order to prevent a thermal spike, in the case of ${ }^{129} I$ transmutation, ${ }^{99} \mathrm{Tc}$ metal pins were installed in the outermost two layers and ${ }^{129} \mathrm{I}$ pins containing a mixture of $\mathrm{BaI}_{2}$ and moderator $\mathrm{YH}_{2}$ were installed in the inner part of the assembly. As a result, the thermal neutrons emitted from the fuel regions are absorbed by ${ }^{99} \mathrm{Tc}$, which has a large neutron 
absorption cross section, so that a thermal spike of the adjacent fuel can be reduced. Figure 1 (b) shows the arrangement of the ${ }^{99} \mathrm{Tc}$ and ${ }^{129} \mathrm{I}$ pins in the assembly. As shown in Fig. 2, 86 assemblies of ${ }^{99} \mathrm{Tc}$ and ${ }^{129} \mathrm{I}$ were loaded in the first layer of the blanket region.

For ${ }^{79} \mathrm{Se}$, it is known that the transmutation rate did not change significantly regardless of whether the moderator is $\mathrm{YD}_{2}$ or $\mathrm{YH}_{2}$; therefore, $\mathrm{YD}_{2}$ was used to address the issue of thermal spike. As shown in Fig. 1 (c), 169 pins in the form of mixed $\mathrm{ZnSe}^{41,42}$ and $\mathrm{YD}_{2}$ were arranged in the assembly ${ }^{30,31}$. As shown in Fig. 2, ten ${ }^{79} \mathrm{Se}$ assemblies were placed in the first layer of the blanket region. This is because the amount of ${ }^{79} \mathrm{Se}$ produced in the fast breeder reactor is as small as $0.22 \mathrm{~kg} / \mathrm{y}$.

It is considered possible to achieve the breeding of fissile materials by the axis blanket, as significant breeding by the radial blanket cannot be expected because the LLFP assemblies are loaded in the first layer of the radial blanket. The thickness of the upper and lower axial blankets were $30 \mathrm{~cm}$ and $40 \mathrm{~cm}$, respectively. Figure 3 shows a cross-sectional view of the core.

Table 1 shows the analysis results of MA transmutation. The composition of the loaded MA nuclides was based on the composition of fuel discharged from the fast breeder reactor, as shown in Table 2, and the composition of fuel discharged from a light water reactor was also studied as a reference. ${ }^{244} \mathrm{Cm}$ was excluded from the loaded MA nuclides because it has a short half-life of 18.1 years and $\mathrm{Cm}$ element can be separated from $\mathrm{MA}^{43}$. Since the MA composition of the fuel discharged from the fast breeder reactor changes due to transition from $\mathrm{Pu}, \mathrm{Am}$ nuclides increase. On the other hand, since the MA composition of fuel discharged from the LWR changes due to transition from $\mathrm{U},{ }^{237} \mathrm{~Np}$ increases. In the case of the MA composition of fuel discharged from the fast breeder reactor, it was found that a support ratio of 1 or more can be achieved for each of the three MA nuclides. The transmutation rate was $10.3 \% / \mathrm{y}$ for ${ }^{237} \mathrm{~Np}, 14.1 \% / \mathrm{y}$ for ${ }^{241} \mathrm{Am}$, and $9.9 \% / \mathrm{y}$ for ${ }^{243} \mathrm{Am}$. Since the transmutation characteristics are excellent, it is considered that the fast breeder reactor system can transmute MA flexibly according to the MA inventory. In the case of the MA composition of the fuel discharged from LWR, the support ratio was as large as 25.6 for ${ }^{237} \mathrm{~Np}$, but it was just 1.0 for ${ }^{243} \mathrm{Am}$. Regarding the transmutation rate, ${ }^{237} \mathrm{~Np}$ and ${ }^{241} \mathrm{Am}$ were greater than $10 \% / \mathrm{y}$, but ${ }^{243} \mathrm{Am}$ was as small as 5.8\%/y. When using MA with the composition of the fuel discharged from LWR, it is considered that efficient MA transmutation can be achieved by mixing it with the MA composition of fuel discharged from the fast breeder reactor.

Table 3 shows the analysis results of LLFP transmutation. The SR is 1.13 for ${ }^{99} \mathrm{Tc}, 1.24$ for ${ }^{129} \mathrm{I}$, and 3.3 for ${ }^{79} \mathrm{Se}$, all exceeding 1 . Regarding the transmutation rate, ${ }^{99} \mathrm{Tc}$ was $0.79 \% / \mathrm{y}$, ${ }^{129} \mathrm{I}$ was $1.24 \% / \mathrm{y}$, and ${ }^{79} \mathrm{Se}$ was $3.3 \% / \mathrm{y}$. The transmutation rates of ${ }^{99} \mathrm{Tc}$ and ${ }^{129} \mathrm{I}$ were lower than the values obtained for $300 \mathrm{MWe}$ class fast reactors $\left({ }^{99} \mathrm{Tc}: 2.47 \% / \mathrm{y},{ }^{129} \mathrm{I}: 3.41 \% / \mathrm{y}\right)$. This is because the leakage of neutron flux in the radial direction is reduced due to the increase in the core diameter. Since the number of loaded assemblies of ${ }^{79} \mathrm{Se}$ is as small as 10 , the transmutation rate of ${ }^{79} \mathrm{Se}$ was not significantly affected by the size of the core. 
Table 4 shows a comparison of the breeding ratios between the fast breeder reactor loaded with MA and LLFP and a normal large-scale fast breeder reactor (with radial blanket). Compared with a normal large-scale fast breeder reactor, the breeding ratio of the fast breeder reactor loaded with MA and LLFP was slightly lower, but it was found that about 1.1 of the breeding ratio could be obtained. This is because the contribution of the breeding ratio of the axial blanket in a large-scale fast breeder reactor is larger than that of the radial blanket; and the breeding ratio of the entire core does not decrease significantly even if the first layer of the radial blanket is replaced with the LLFP assemblies.

The sodium void reactivity and the Doppler coefficients related to the safety of the fast breeder reactor loaded with MA and LLFP were analyzed. Table 5 shows a comparison of the sodium void reactivity and the Doppler coefficient between the fast breeder reactor loaded with MA and LLFP and a normal large-scale fast breeder reactor. The sodium void reactivity of the fast breeder reactor loaded with MA and LLFP was about 30\% higher than that of the normal large-scale fast breeder reactor. The absolute value of the Doppler coefficient was about $40 \%$ smaller. This is because the neutron spectrum of the core became harder due to the addition of MA. However, it is considered that there is no major safety problem with such changes in the Doppler coefficient and sodium void reactivity.

Regarding MA, the difference in transmutation rate between MA-containing Duplex pellets and homogeneous MA pellets was analyzed. As shown in Table 6, it was found that there was no significant difference in transmutation rate between MA-containing Duplex pellets and homogeneous MA pellets, and it was found that MA-containing Duplex pellets were effective. Since the energy spectrum of neutrons is hard in the core, the self-shielding effect by inserting MA in the central region is considered to be small.

\section{Conclusions}

From this study, the new concept of fast breeder reactor system that can transmute MA $\left({ }^{237} \mathrm{~Np},{ }^{241} \mathrm{Am}\right.$, $\left.{ }^{243} \mathrm{Am}\right)$ and LLFP $\left({ }^{129} \mathrm{I},{ }^{99} \mathrm{Tc}\right.$, $\left.{ }^{79} \mathrm{Se}\right)$ with a support ratio of 1 or more was constructed while breeding fissile materials in one fast breeder reactor. It was clarified that this fast breeder reactor achieved a breeding ratio of about 1.1, and MA and LLFP support ratios of 1 or more. The transmutation rate was $10.3 \% / \mathrm{y}$ for ${ }^{237} \mathrm{~Np}, 14.1 \% / \mathrm{y}$ for ${ }^{241} \mathrm{Am}, 9.9 \% / \mathrm{y}$ for ${ }^{243} \mathrm{Am}, 1.6 \% / \mathrm{y}$ for ${ }^{129} \mathrm{I}, 0.75 \% / \mathrm{y}$ for ${ }^{99} \mathrm{Tc}$, and $4 \% / \mathrm{y}$ for ${ }^{79} \mathrm{Se}$.

Based on these studies, the following can be considered impacts on nuclear power development, effective utilization of uranium resources, and reduction of radioactive waste.

- By simultaneously breeding fissile materials and transmuting MA and LLFP in one fast reactor, it will be possible to solve the long-term issues of the nuclear power systems, such as securing nuclear fuel resources and reducing radioactive waste. In addition, solving these issues would promote a better understanding of nuclear power systems among the general public.

- The ability to breed fissile materials and transmute MA and LLFP in one fast breeder reactor shows 
the high potential of the fast breeder reactor and will promote research and development of the fast breeder reactor.

- This new system can contribute to the effective utilization of uranium resources and the reduction of radioactive waste without significantly changing the conventional nuclear fuel cycle system.

\section{Method}

\section{Core conditions}

The fast breeder reactor used in this study is a large sodium-cooled fast breeder reactor designed for the commercial stage. Table 7 shows the main specifications. The thermal power of the reactor is 3570 MWt and the electric power is $1500 \mathrm{MWe}$. The core was a homogeneous two-region core, with 316 MA-containing fuel assemblies in the inner core, $278 \mathrm{MA}$-containing fuel assemblies in the outer core, and 55 control rods. The outside of the core was composed of 96 LLFP assemblies, 102 radial blanket assemblies, and 222 radial shielding assemblies. The height of the core is $80 \mathrm{~cm}$. The core equivalent diameter is $490 \mathrm{~cm}$. The Pu enrichment of the inner and outer cores are $20.7 \mathrm{~W} \%$ and $23.3 \mathrm{wt} \%$, respectively. The Pu enrichment of the outer core is higher than that of the inner core to achieve power flattening. Table 8 shows the specifications of the MA-containing fuel assembly and the LLFP assembly. There are 271 MA-containing fuel pins in the fuel assembly and 169 LLFP pins in the LLFP assembly. The isotopic compositions of MA and LLFP loaded in the fast breeder reactor shown in Tables 2 and 9 were based on the results of $80 \mathrm{GWd} / \mathrm{t}$ burnup simulation in the fast breeder reactor by MVP-BURN code. The MA composition of the discharged LWR fuel was based on the results of a 40

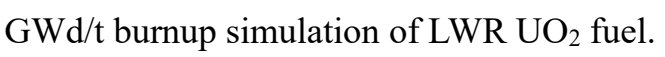

\section{Calculational method}

Core characteristics were analyzed with a continuous neutron energy Monte Carlo code MVP ${ }^{44}$ with JENDL-4. $0^{45}$ neutron cross section library. The number of neutron histories was 10,000 , the number of batches skipped for accurate source distribution was 100, and the number of effective batches was 1,000. From this Monte Carlo simulation, the neutron energy spectra and the reaction rates of MA and LLFP in various regions of the fast breeder reactor were obtained. The typical statistical error for $\mathrm{k}$ effective was about $0.015 \%$ with a $1 \sigma$ error. The statistical errors of the MA reaction rate in the core fuel and the reaction rate of the LLFP in the LLFP assembly were also sufficiently low, ranging from 0.1 and $0.5 \%$. Burnup calculations were performed with the MVP-BURN code ${ }^{46}$. 


\section{References}

1. Gray, W. J., Fission product transmutation effects on high-level radioactive waste forms. Nature $\mathbf{2 9 6}$, 547-549 (1982)

2. Ramspott, L. D. et al., Impacts of new developments in partitioning and transmutation on the disposal of high-level nuclear waste in a mined geologic repository (1992).

3. Salvatores, M., Slessarev, I. \& Uematsu, M., A global physics approach to transmutation of radioactive nuclei. Nuclear Science and Engineering 116, 1-18 (1994).

4. Walker, C. \& Nicolaou, G., Transmutation of neptunium and americium in a fast neutron flux: EPMA results and KORIGEN predictions for the superfact fuels. Journal of Nuclear Materials 218, 129-138 (1995).

5. Kloosterman, J. L. \& Li, J., Transmutation of Tc-99 and I-129 in fission reactors. A calculational study. In Netherlands Energy Research Foundation (ECN), Petten (Netherlands). Funding organisation: Commission of the European Communities, Brussels (Belgium) (1995).

6. Tommasi, J., Delpech, M., Grouiller, J.-P. \& Zaetta, A., Long-lived waste transmutation in reactors. Nuclear Technology 111, 133-148 (1995).

7. Wakabayashi, T., Takahashi, K.,\& Yanagisawa, T., Feasibility Studies on Plutonium and Minor Actinide Burning in Fast Reactors. Nuclear Technology 118, 14-25 (1997).

8. Salvatores, M., Slessarev, I., Uematsu, M. \& Tchistiakov, A., The neutronic potential of nuclear power for long-term radioactivity risk reduction. Progress in Nuclear Energy 32, 471-475 (1998).

9. Wakabayashi, T. \& Higano, N., Study on MA and FP transmutation in fast reactors. Progress in Nuclear Energy 32, 555-562 (1998).

10. OECD-NEA. Actinide and fission product partitioning and transmutation Status and assessment report (1999).

11. Hwang, I. et al., The concept of proliferation-resistant, environment-friendly, accident-tolerant, continual and economical reactor (PEACER). Progress in Nuclear Energy 37, 217-222 (2000).

12. Messaoudi, N. \& Tommasi, J., Fast burner reactor devoted to minor actinide incineration. Nuclear Technology 137, 84-96 (2002).

13. Wakabayashi, T., Transmutation characteristics of MA and LLFP in a fast reactor. Progress in Nuclear Energy 40, 457-463 (2002).

14. Suzuki, M., Ezoubtchenko, A., Akatsuka, H., Matsuura, H. \& Takagi, R., Isotope separation required in SCNES and future subjects. Progress in Nuclear Energy 40, 561-568 (2002).

15. Takaki, N. \& Mizuno, T., Design study on sodium-cooled fast reactor core loaded with LLFP transmutation sub-assemblies. In Proceedings of GENES4/ANP2003 (2003).

16. Salvatores, M., Nuclear fuel cycle strategies including partitioning and transmutation. Nucl. Eng. Des. 235, 805-816 (2005).

17. Aoyama, T., Maeda, S., Maeda, Y. \& Suzuki, S., Transmutation of technetium in the experimental 
fast reactor JOYO. Journal of Nuclear and Radiochemical Sciences 6, 279-282 (2005).

18. OECD-NEA. Advanced Nuclear Fuel Cycles and Radioactive Waste Management (2006).

19. Warin, D., Status of the French research on partitioning and transmutation. In MRS Proceedings (2006).

20. OECD-NEA. Physics and Safety of Transmutation Systems, A Status Report (2006).

21. OECD-NEA. Regulating the long-term safety of geological disposal Towards a common understanding of the main objectives and bases of safety criteria (2007).

22. Osaka, M. et al., Research and development of minor actinide-containing fuel and target in a future integrated closed cycle system. Journal of Nuclear Science and Technology 44, 309-316 (2007).

23. Yokoyama, T., Wakabayashi, T., Tachi, Y., Takaki, N. \& Matsuyama, S., New target concepts for increase in transmutation rate of LLFPs in FBR recycle system. In Proceedings of International Conference on the Nuclear Fuel Cycle (2009).

24. Tachi, Y., Wakabayashi, T. \& Yokoyama, T., Study on target fabrication for LLFP transmutation by fast reactors. In Proceedings of Global 2009, Paris (2009).

25. OECD-NEA. Potential Benefits and Impacts of Advanced Nuclear Fuel Cycles with Actinide Partitioning and Transmutation (2011).

26. Gonzalez-Romero, E., Impact of partitioning and transmutation on the high level waste management. Nuclear Engineering and Design 241, 3436-3444 (2011).

27. Liu, B. et al., Transmutation of minor actinides in the pressurized water reactors. Annals of Nuclear Energy 64, 86-92 (2014).

28. Chiba, S., Wakabayashi, T., Tachi, Y., Takaki, N., Terashima, A., Okumura, S., \& Yoshida, T., Method to Reduce Long-lived Fission Products by Nuclear Transmutations with Fast Spectrum Reactors, Scientific Reports (2017) 7: 13961, DOI:10.1038/ s41598-017-14319-7.

29. Wakabayashi, T., Takahashi, M., Chiba, S., Takaki, N., Tachi, Y. \& Tahara, Y., Core concept of simultaneous transmutation of six LLFP nuclides using a fast reactor, Nuclear Engineering and Design 352 (2019) 110208: https://doi.org/10.1016/j.nucengdes.2019.110208.

30. Wakabayashi, T., Tachi, Y., Takahashi, M., Chiba, S., \& Takaki, N., Study on method to achieve high transmutation of LLFP using fast reactor, Scientific Reports (2019) 9:19156.

31 Wakabayashi, T., Takahashi, M., Chiba, S., Takaki, N., \& Tachi, Y., A fast reactor transmutation system for 6 LLFP nuclides, Nuclear Engineering and Design 363 (2020) 110667.

32. Volckaert, G. \& Mallants, D., LONG-TERM ENVIRONMENTAL IMPACT OF UNDERGROUND DISPOSAL OF P\&TWASTE, https://www.oecd-nea.org/pt/docs/iem/mol98/session6/SVIpaper1.pdf.

33. Song, W. K, et al., High burnup fuel technology in Korea, Nuclear Engineering and Technology, Vol.40 No.1,21-36, Feb. 2008.

34. Kato, M., Kohno, S., and Kamimura, K., Development of Duplex type $\mathrm{MOX}-\mathrm{Gd}_{2} \mathrm{O}_{3}$ fuel for water reactors, Technical Committee Meeting on Advances in Pellet Technology for Improved 
Performance and High Burnup, 1996/10, Tokyo Japan (1996).

35. Toshio Wakabayashi, Makoto Takahashi, Naoyuki Takaki, Yoshiaki Tachi and Mari Yano:" Conceptual Study on Recriticality Prevention Core Having Duplex Pellets with Neutron Absorber in Outer Core in a Fast Reactor" Science and Technology of Nuclear Installations, vol. 2019, Article ID 2753789, 6 pages, 2019.

36. Vetrano, J., Hydrides as neutron moderator and reflector materials. Nuclear Engineering and Design 14, 390-412 (1971).

37. Yokoyama, T., Wakabayashi, T., Tachi, Y. \& Nagata, A., Optimizing pin layout in transmutation rate of long-life FP with deuteride moderator for fast reactors. In Proceedings of GLOBAL 2011, Makuhari, Japan (2011).

38. Wakabayashi, T., Improvement of core performance by introduction of moderators in a blanket region of fast reactors. Science and Technology of Nuclear Installations 2013 (2013).

39. Tachi, Y., Wakabayashi, T., Fabrication of $\mathrm{BaI}_{2}-\mathrm{ZrH}_{2}-\mathrm{x}$ Composite for I-129 Transmutation Target, Proceedings of GLOBAL2011, Makuhari, Japan, Dec. 11-16, 2011.

40. Konings, R.J.M., Stalios, A.D., Walker, C.T., Cocuaud, N., Transmutation of technetium: results of the EFTTRA-T1 experiment, J. Nuclear Materials 245, 122-128(1998).

41. Korostelin, Y.Y., Kozlovsky, V.I., Nasibov, A.S. and Shapkin, P.V., Vapour growth and characterization of bulk ZnSe single crystals. J. Crystal Growth 161, p.51(1996).

42. BABA, N., HATTORI, S., KAWASAKI, K. and OZAKI, Y., Preparation of ZnSe by Thermal Decomposition of Metal Alkoxide, Journal of the Ceramic Society of Japan 105 [7] 606-610, 1997.

43. Suzuki, H., et al., Continuous extraction and separation of Am (III) and Cm (III) using a highly practical diamide amine extractant, Journal of Nuclear Science and Technology, Vol.54, No11, 11631167 (2017).

44. Mori, T. \& Nakagawa, M., MVP/GMVP: general purpose Monte Carlo codes for neutron and photon transport calculations based on continuous energy and multigroup methods. JAERI Data/Code (1994). JAERI-Data/Code-94-007.

45. Shibata, K., et al., JENDL-4.0: a new library for nuclear science and engineering. Journal of Nuclear Science and Technology 48, 1-30 (2011).

46. Okumura, K., Mori, T., Nakagawa, M. \& Kaneko, K., Validation of a continuous-energy Monte Carlo burn-up code MVP-BURN and its application to analysis of post irradiation experiment. Journal of Nuclear Science and Technology 37, 128-138 (2000). 


\begin{tabular}{|l|c|c|c|c|c|c|}
\hline Fuel composition & \multicolumn{3}{|l|}{$\begin{array}{l}\text { MA abundance of discharged } \\
\text { FBR fuel }\end{array}$} & \multicolumn{3}{|l|}{$\begin{array}{l}\text { abundance of } \\
\text { discharged LWR fuel }\end{array}$} \\
\hline Nuclide & ${ }^{237} \mathrm{~Np}$ & ${ }^{241} \mathrm{Am}$ & ${ }^{243} \mathrm{Am}$ & ${ }^{237} \mathrm{~Np}$ & ${ }^{241} \mathrm{Am}$ & ${ }^{243} \mathrm{Am}$ \\
\hline $\begin{array}{l}\text { Transmutation rate } \\
(\% / y)\end{array}$ & 10.3 & 14.1 & 9.9 & 12.4 & 14.0 & 5.8 \\
\hline SR & 4.6 & 6.3 & 4.4 & 25.6 & 4.6 & 1.0 \\
\hline
\end{tabular}

Table 1 Transmutation rate and support ratio of MA

\begin{tabular}{|c|c|c|c|}
\hline & \multicolumn{2}{|c|}{ Fuel composition } & \multirow{2}{*}{$\begin{array}{c}\text { Half-life } \\
\text { (year) }\end{array}$} \\
\hline & $\begin{array}{l}\text { MA abundance of } \\
\text { discharged FBR fuel } \\
(\%)\end{array}$ & $\begin{array}{l}\text { MA abundance of } \\
\text { discharged LWR fuel } \\
(\%)\end{array}$ & \multicolumn{2}{|c|}{50.5} & $2,144,000$ \\
\hline${ }^{237} \mathrm{~Np}$ & 11.3 & 37.0 & 433 \\
\hline${ }^{241} \mathrm{Am}$ & 51.3 & 12.5 & 7370 \\
\hline${ }^{243} \mathrm{Am}$ & 37.4 & & \\
\hline
\end{tabular}

Table 2 Isotope abundance and half-life of loaded MA nuclides

\begin{tabular}{|l|c|c|c|}
\hline & ${ }^{99} \mathrm{Tc}$ & ${ }^{129} \mathrm{I}$ & ${ }^{79} \mathrm{Se}$ \\
\hline Transmutation rate(\%/y) & 0.75 & 1.4 & 4.0 \\
\hline SR & 1.13 & 1.24 & 3.3 \\
\hline
\end{tabular}

Table 3 Transmutation rate and support ratio of LLFP in fast breeder reactor with MA and LLFP 


\begin{tabular}{|c|c|c|}
\hline Core arrangement & $\begin{array}{l}\text { FBR with MA and } \\
\text { LLFP }\end{array}$ & $\begin{array}{l}\text { FBR without MA and } \\
\text { LLFP }\end{array}$ \\
\hline Core & 0.76 & 0.76 \\
\hline Axial blanket & 0.32 & 0.32 \\
\hline Radial blanket & 0.01 & 0.11 \\
\hline Total & 1.09 & 1.19 \\
\hline
\end{tabular}

Table 4 Comparison of breeding ratios between with and without MA and LLFP

\begin{tabular}{|l|c|c|}
\hline \multicolumn{1}{|c|}{ Core arrangement } & $\begin{array}{l}\text { FBR with MA and } \\
\text { LLFP }\end{array}$ & $\begin{array}{l}\text { FBR without MA and } \\
\text { LLFP }\end{array}$ \\
\hline Sodium void reactivity $(\$)$ & 6.8 & 5.2 \\
\hline Doppler coefficient $(\mathrm{Tdk} / \mathrm{dT})$ & $-4.0 \mathrm{E}-3$ & $-6.6 \mathrm{E}-3$ \\
\hline
\end{tabular}

Table 5 Characteristics of sodium void reactivity and Doppler coefficient in the core of fast breeder reactor

\begin{tabular}{|c|c|c|}
\hline & \multicolumn{2}{|c|}{ Transmutation rate (\%) } \\
\hline Pellet arrangement & $\begin{array}{l}\text { Duplex pellet with } \\
\text { MA in the center } \\
\text { region (MA:20\%) }\end{array}$ & $\begin{array}{l}\text { Homogeneous pellet } \\
\text { with MA (MA:5\%) }\end{array}$ \\
\hline${ }^{237} \mathrm{~Np}$ & 14.1 & 14.3 \\
\hline${ }^{241} \mathrm{Am}$ & 10.3 & 10.5 \\
\hline
\end{tabular}

Table 6 Comparison of transmutation rate between Duplex pellet and homogeneous pellet 


\begin{tabular}{|l|l|}
\hline Thermal power (MWt) & 3570 \\
\hline Electric power (MWe) & 1500 \\
\hline Core type & Homogeneous two-region core \\
\hline Operation cycle length (months) & 18 \\
\hline $\begin{array}{l}\text { Number of refueling batches } \\
\text { (Core/Blanket) }\end{array}$ & $4 / 4$ \\
\hline Core height (cm) & 80 \\
\hline $\begin{array}{l}\text { Thickness of axial blanket (cm) } \\
\text { (Upper/Lower) }\end{array}$ & $30 / 40$ \\
\hline $\begin{array}{l}\text { Number of core fuel assemblies } \\
\text { (Inner/Outer/Total) }\end{array}$ & $316 / 278 / 594$ \\
\hline $\begin{array}{l}\text { Number of LLFP assemblies } \\
\text { (In) }\end{array}$ & assembly:10) \\
\hline Number of radial blanket assemblies & 102 \\
\hline $\begin{array}{l}\text { Pu enrichment (wt\%) } \\
\text { (Inner/Outer core) }\end{array}$ & $20.7 / 23.3$ \\
\hline $\begin{array}{l}\text { Number of control rods } \\
\text { (Main/backup) }\end{array}$ & $40 / 15$ \\
\hline $\begin{array}{l}\text { Number of radial shielding } \\
\text { assemblies }\end{array}$ & $108 / 114$ \\
\hline $\begin{array}{l}\text { Volume ratio of core } \\
\text { (Fuel/Structure/Coolant) }\end{array}$ & $44.1 / 24.2 / 31.7$ \\
\hline
\end{tabular}

Table 7 Specification of large-scale fast breeder reactor for MA and LLFP transmutation 


\begin{tabular}{|l|c|c|}
\hline & $\begin{array}{l}\text { MA- } \\
\text { containing } \\
\text { fuel assembly }\end{array}$ & $\begin{array}{l}\text { LLFP } \\
\text { assembly }\end{array}$ \\
\hline Pin diameter (mm) & 8.8 & 11.5 \\
\hline Thickness of pin (mm) & 0.52 & 0.5 \\
\hline Pellet diameter (mm) & 7.6 & 10.3 \\
\hline Number of pins in the assembly & 271 & 169 \\
\hline
\end{tabular}

Table 8 Specifications of MA-containing fuel assembly and LLFP assembly

\begin{tabular}{|c|c|c|}
\hline $\begin{array}{c}\text { Isotopes of loaded } \\
\text { LLFP elements }\end{array}$ & $\begin{array}{c}\text { Abundance } \\
(\%)\end{array}$ & $\begin{array}{c}\text { Half-life of LLFP } \\
\text { (year) }\end{array}$ \\
\hline${ }^{76} \mathrm{Se}$ & 0.027 & \\
\hline${ }^{77} \mathrm{Se}$ & 2.786 & \\
\hline${ }^{78} \mathrm{Se}$ & 5.587 & 295,000 \\
\hline${ }^{79} \mathrm{Se}$ & 13.32 & \\
\hline${ }^{80} \mathrm{Se}$ & 22.75 & 211,000 \\
\hline${ }^{82} \mathrm{Se}$ & 55.52 & \\
\hline${ }^{99} \mathrm{Tc}$ & 100.00 & $15,700,000$ \\
\hline${ }^{127} \mathrm{I}$ & 23.91 & \\
\hline${ }^{129} \mathrm{I}$ & 76.09 & \\
\hline
\end{tabular}

Table 9 Isotope abundance and half-life of loaded LLFP nuclides 


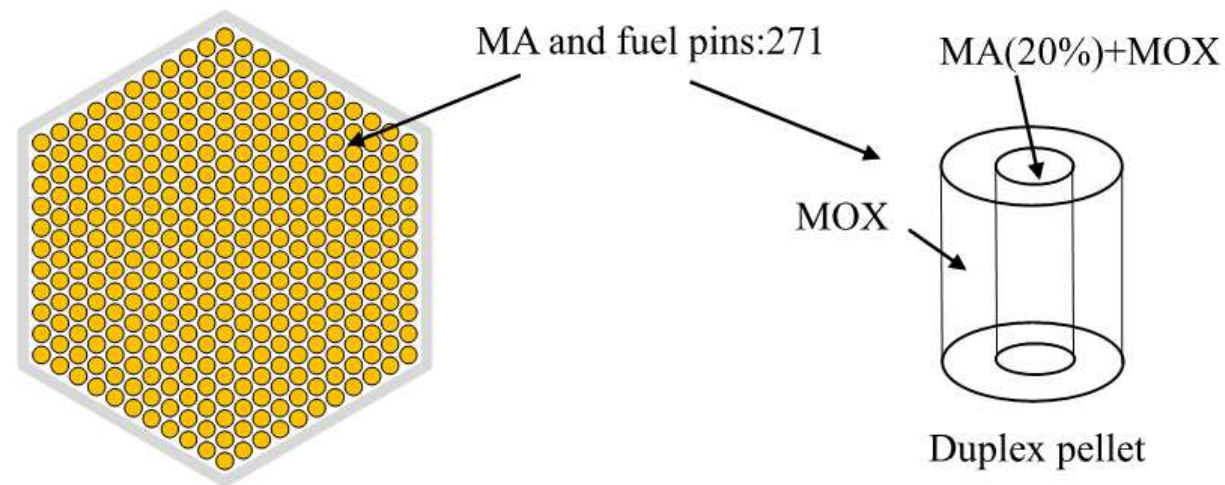

(a) MA and fuel assembly

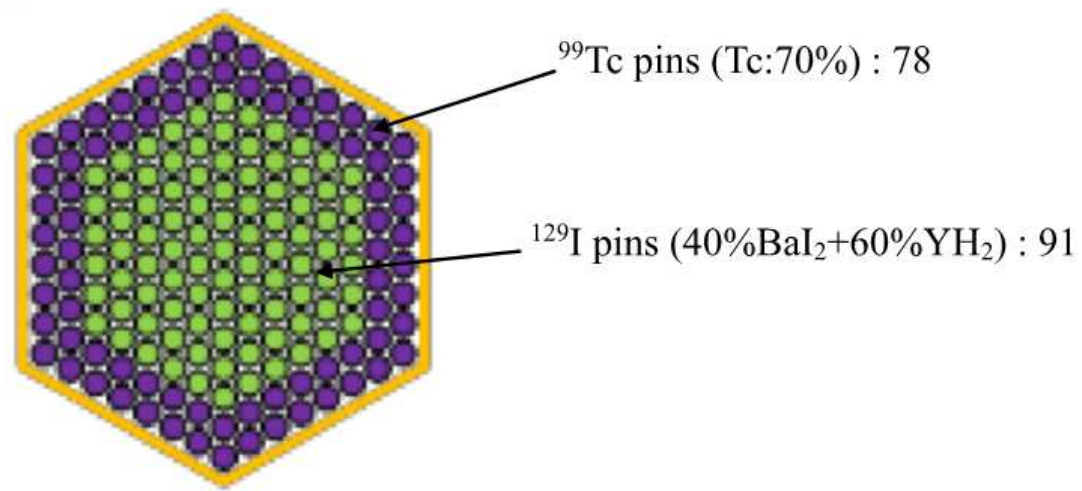

(b) ${ }^{129} \mathrm{I}$ and ${ }^{99} \mathrm{Tc}$ assembly

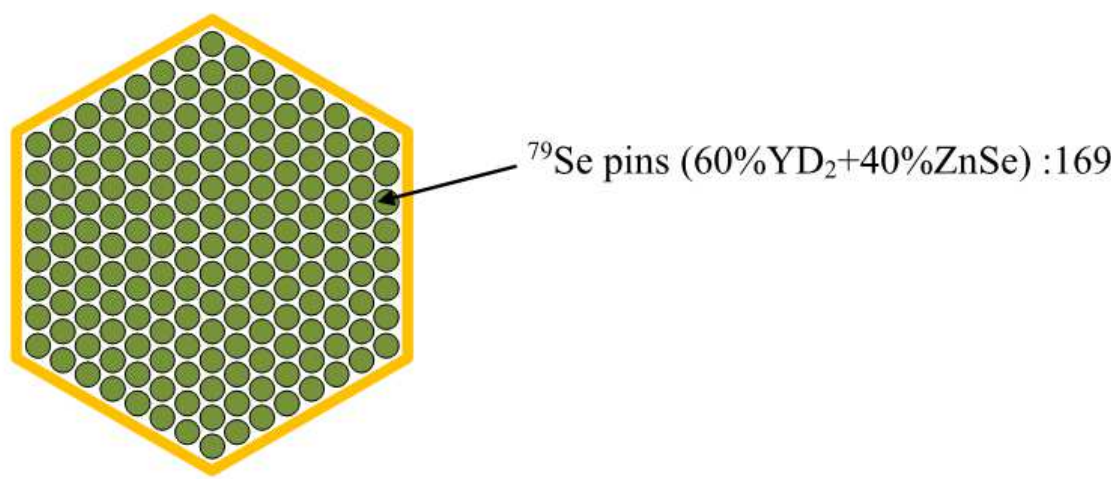

(c) ${ }^{79} \mathrm{Se}$ assembly

Fig. 1 Configurations of MA fuel assembly, ${ }^{129} \mathrm{I}$ and ${ }^{99} \mathrm{Tc}$ assembly, and ${ }^{79} \mathrm{Se}$ assembly (a) the structure of the MA-containing MOX fuel assembly. The number of MA fuel pins in the MAcontaining fuel assembly is 271 . (b) the arrangement of the ${ }^{99} \mathrm{Tc}$ pins and the ${ }^{129} \mathrm{I}$ pins in the assembly. Eighty-six ${ }^{99} \mathrm{Tc}$ and ${ }^{129} \mathrm{I}$ assemblies are loaded in the first layer of the blanket region. (c) 169 pins in the form of mixed $\mathrm{ZnSe}$ and $\mathrm{YD}_{2}$ are arranged in the assembly. Ten ${ }^{79} \mathrm{Se}$ assemblies are placed in the first layer of the blanket region. 

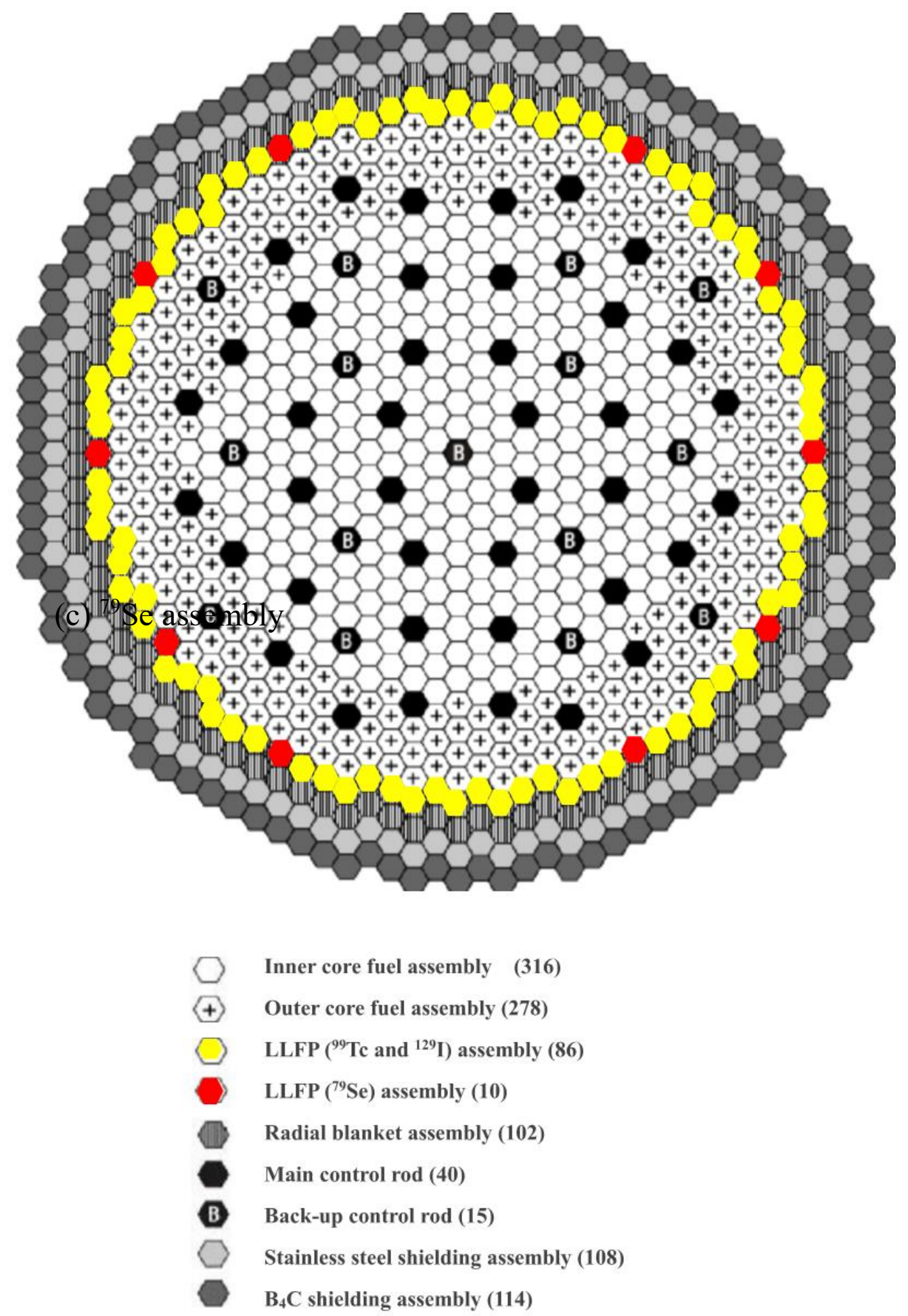

Fig.2 Core arrangement for MA and LLFP transmutation in fast breeder reactor

The core has two homogeneous zones: inner and outer cores. MA fuel assemblies are loaded in the inner and outer cores. The LLFP assemblies are loaded in the first layer of the blanket region. The blanket fuel assemblies are loaded in the second layer of the blanket region. 


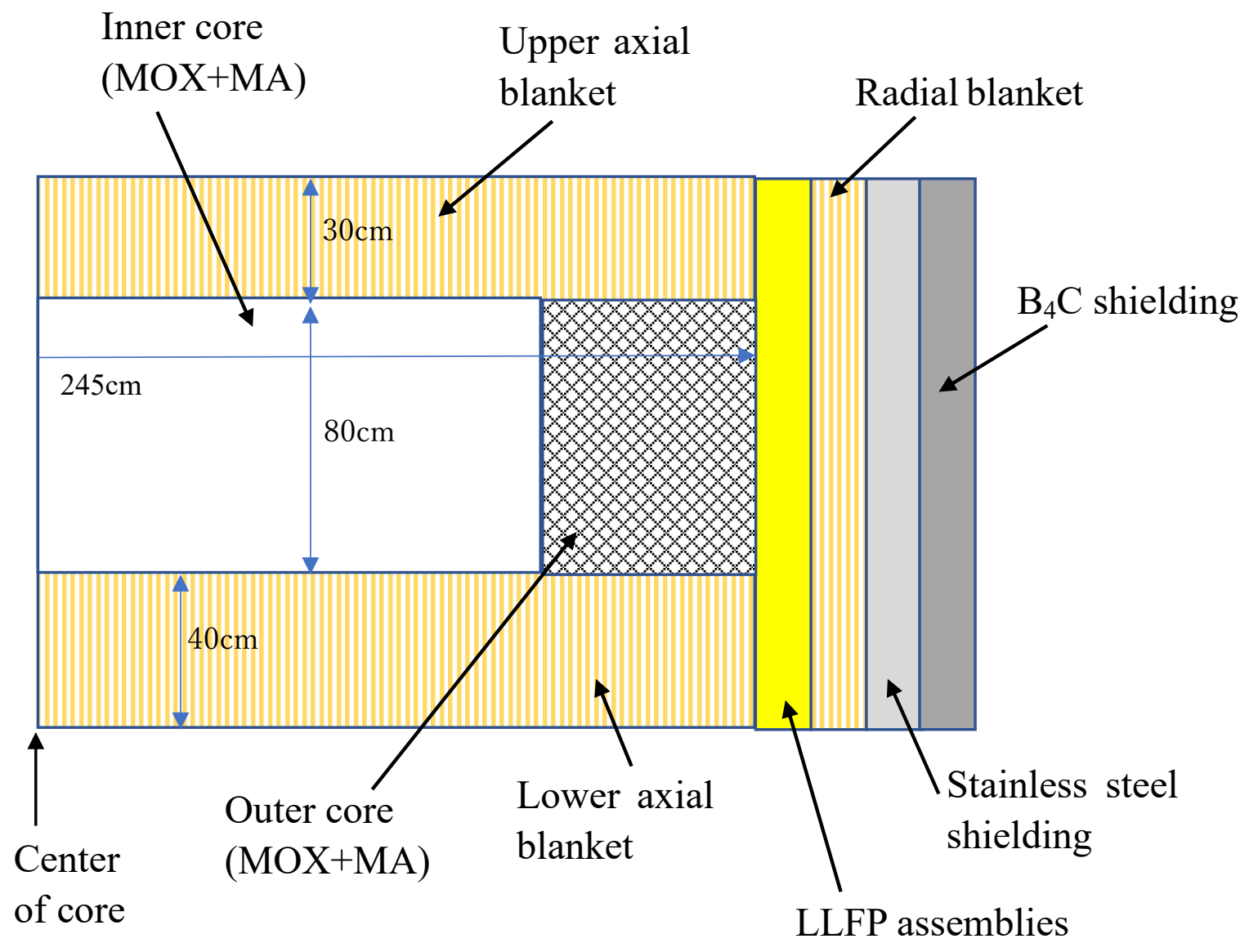

Fig.3 Axial core arrangement for MA and LLFP transmutation in fast breeder reactor The height of the core is $80 \mathrm{~cm}$. The thicknesses of the upper and lower axial blankets are $30 \mathrm{~cm}$ and $40 \mathrm{~cm}$, respectively. The core equivalent diameter is $490 \mathrm{~cm}$. 


\section{Acknowledgements}

We would like to thank Y. Tsuboi from Toshiba Energy Systems \& Solutions Corporation for his assistance in carrying out computational simulations as well as for their helpful suggestions and other valuable input.

\section{Author Contributions}

T.W. conceived the study. T.W. designed the transmutation system and computational simulations. T.W. carried out computational simulations and analyses.

\section{Additional Information}

Competing Interests: The author declares no competing interests. 


\section{Figure legends}

Fig. 1 Configurations of MA fuel assembly, ${ }^{129} \mathrm{I}$ and ${ }^{99} \mathrm{Tc}$ assembly, and ${ }^{79} \mathrm{Se}$ assembly (a) the structure of the MA-containing MOX fuel assembly. The number of MA fuel pins in the MAcontaining fuel assembly is 271 . (b) the arrangement of the ${ }^{99} \mathrm{Tc}$ pins and the ${ }^{129} \mathrm{I}$ pins in the assembly. Eighty-six ${ }^{99} \mathrm{Tc}$ and ${ }^{129} \mathrm{I}$ assemblies are loaded in the first layer of the blanket region. (c) 169 pins in the form of mixed $\mathrm{ZnSe}$ and $\mathrm{YD}_{2}$ are arranged in the assembly. Ten ${ }^{79} \mathrm{Se}$ assemblies are placed in the first layer of the blanket region.

Fig. 2 Core arrangement for MA and LLFP transmutation in fast breeder reactor The core has two homogeneous zones: inner and outer cores. MA fuel assemblies are loaded in the inner and outer cores. The LLFP assemblies are loaded in the first layer of the blanket region. The blanket fuel assemblies are loaded in the second layer of the blanket region.

Fig.3 Axial core arrangement for MA and LLFP transmutation in fast breeder reactor The height of the core is $80 \mathrm{~cm}$. The thicknesses of the upper and lower axial blankets are $30 \mathrm{~cm}$ and $40 \mathrm{~cm}$, respectively. The core equivalent diameter is $490 \mathrm{~cm}$. 


\section{Figures}

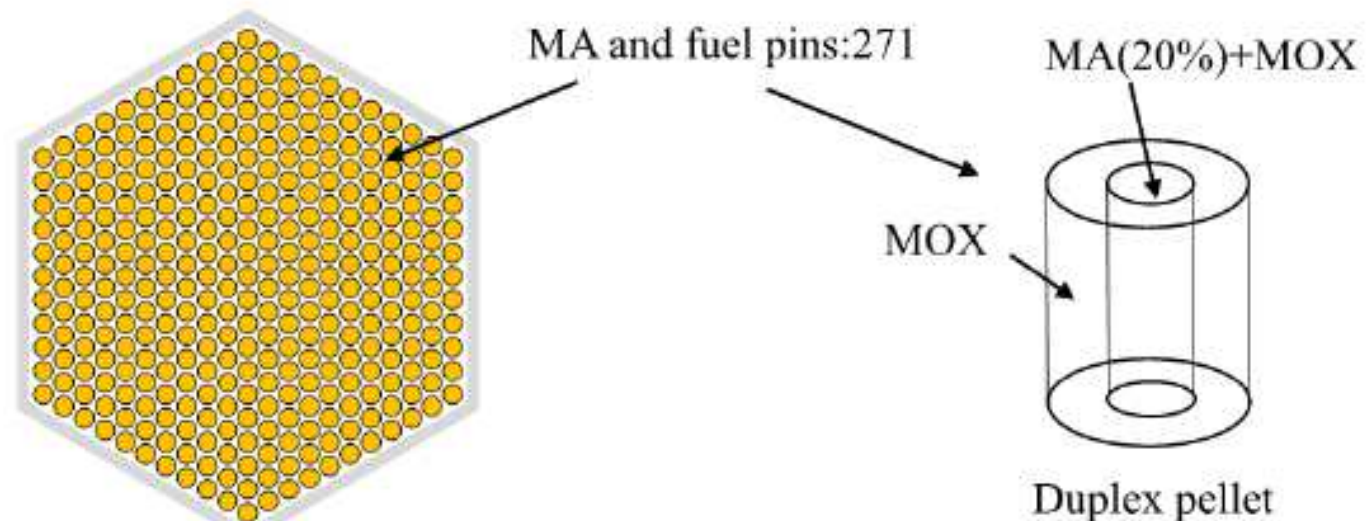

(a) MA and fuel assembly

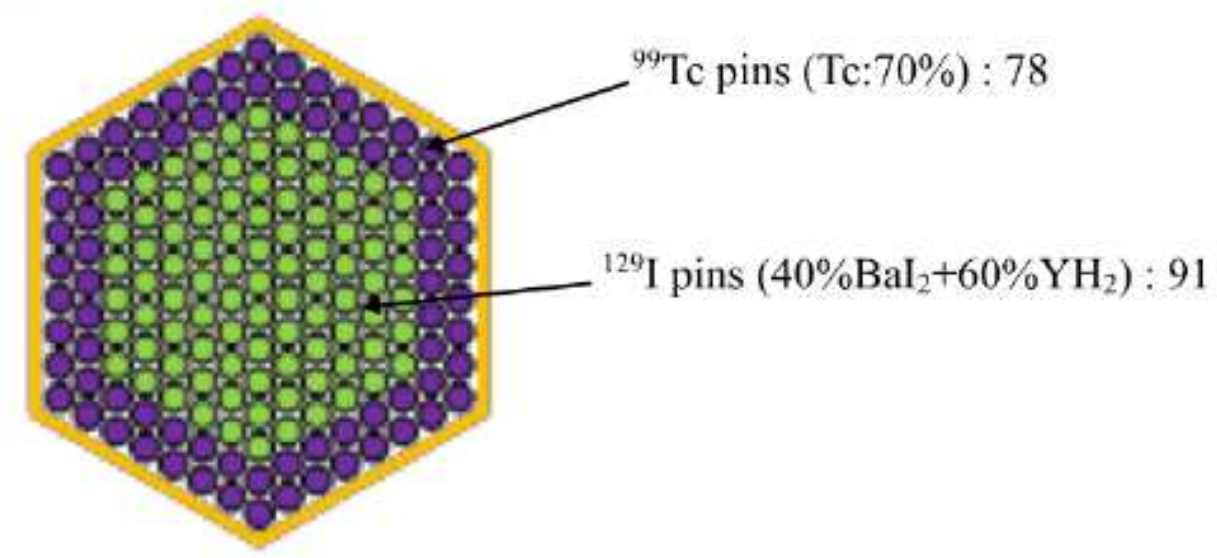

(b) ${ }^{129} \mathrm{I}$ and ${ }^{99} \mathrm{Tc}$ assembly

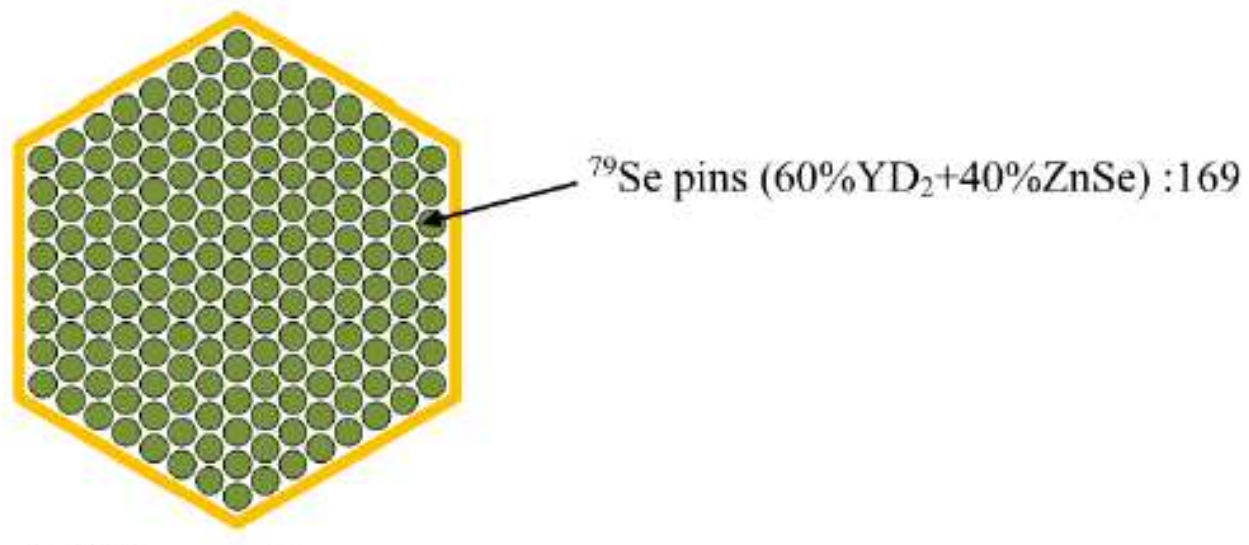

(c) ${ }^{79} \mathrm{Se}$ assembly

\section{Figure 1}

Configurations of MA fuel assembly, $129 \mathrm{I}$ and 99Tc assembly, and 79Se assembly (a) the structure of the MA-containing MOX fuel assembly. The number of MA fuel pins in the MA-containing fuel assembly is 271. (b) the arrangement of the 99Tc pins and the 129I pins in the assembly. Eighty-six 99Tc and 129I 
assemblies are loaded in the first layer of the blanket region. (c) 169 pins in the form of mixed ZnSe and YD2 are arranged in the assembly. Ten 79Se assemblies are placed in the first layer of the blanket region.

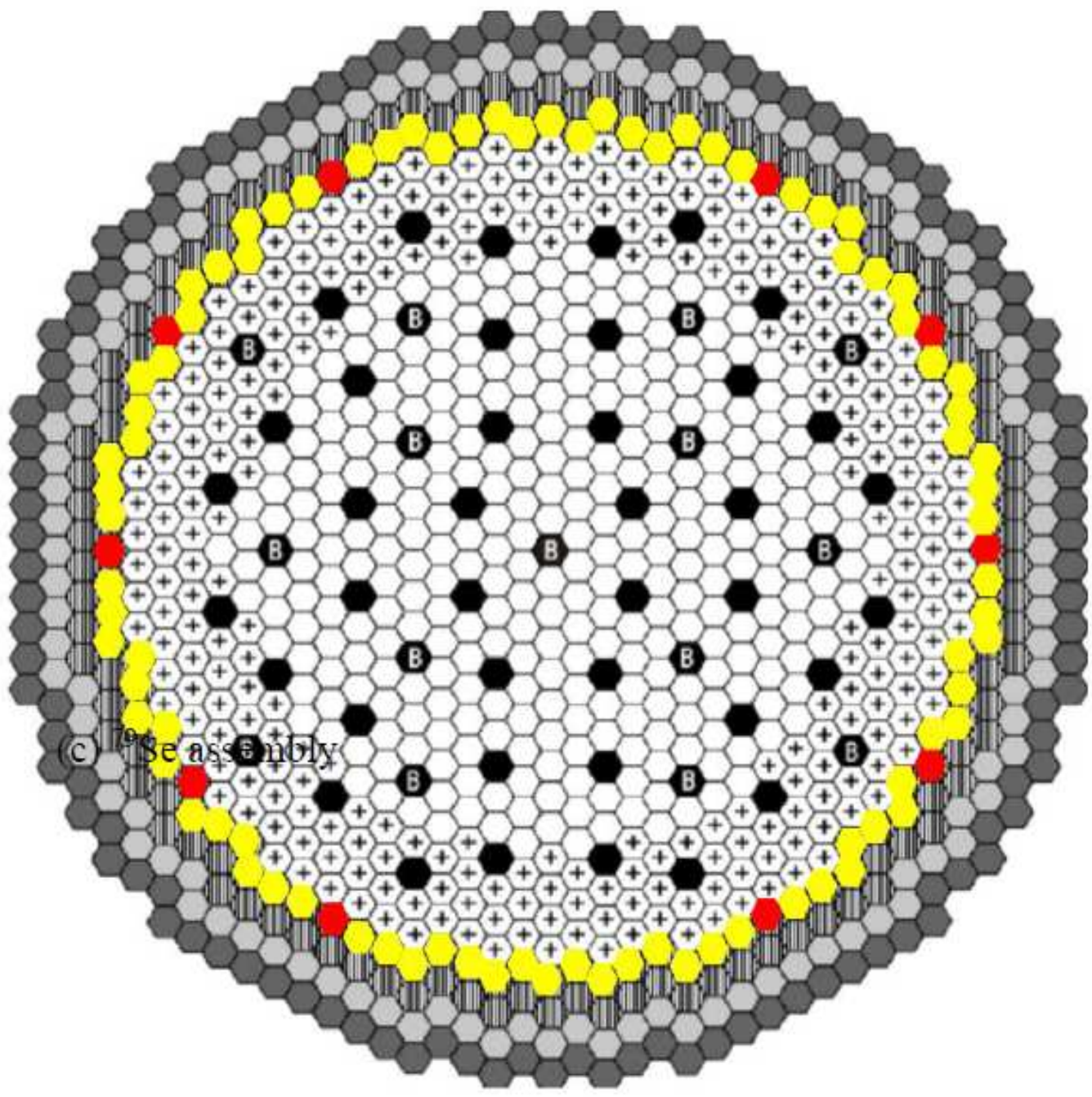

Inner core fuel assembly (316)
+ Outer core fuel assembly (278)
LLFP $\left({ }^{96} \mathrm{Tc}\right.$ and $\left.{ }^{129} \mathrm{I}\right)$ assembly $(86)$
LLFP $\left({ }^{79} \mathrm{Se}\right)$ assembly (10)
Radial blanket assembly (102)
Bain control rod (40)
Back-up control rod (15)
Btainless steel shielding assembly (108)
B 4 C shielding assembly (114)

Figure 2

Core arrangement for MA and LLFP transmutation in fast breeder reactor The core has two homogeneous zones: inner and outer cores. MA fuel assemblies are loaded in the inner and outer cores. The LLFP 
assemblies are loaded in the first layer of the blanket region. The blanket fuel assemblies are loaded in the second layer of the blanket region.

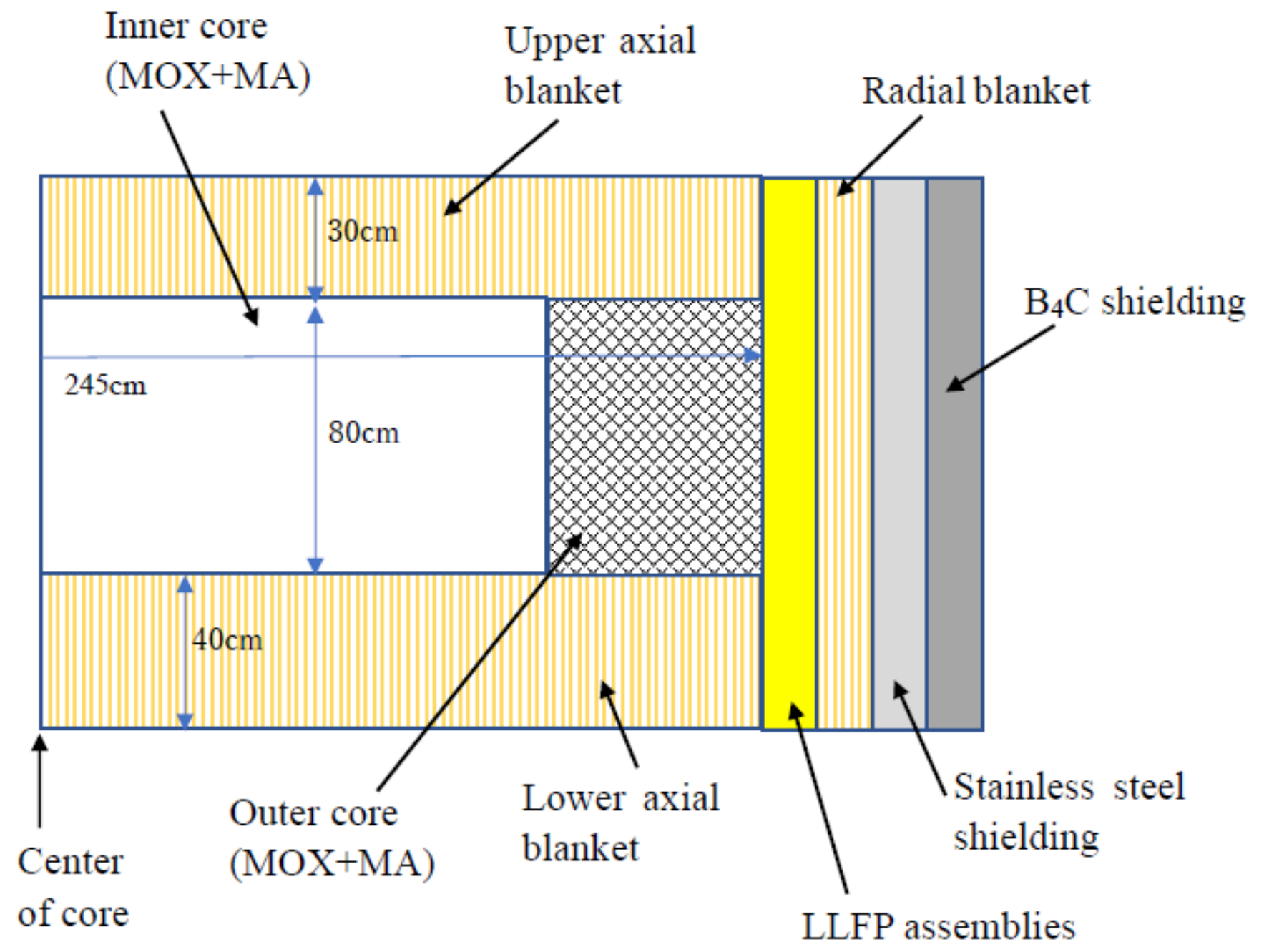

Figure 3

Axial core arrangement for MA and LLFP transmutation in fast breeder reactor The height of the core is $80 \mathrm{~cm}$. The thicknesses of the upper and lower axial blankets are $30 \mathrm{~cm}$ and $40 \mathrm{~cm}$, respectively. The core equivalent diameter is $490 \mathrm{~cm}$. 